\title{
Complexity Uncertainty Analysis of Dynamic in a Dual-Channel Energy Supply Chain Model with Heterogeneous Retailers
}

\author{
Ting Li, ${ }^{1,2}$ Junhai Ma, ${ }^{1}$ and Lijian Sun ${ }^{1,3}$ \\ ${ }^{1}$ School of Economics and Management, Tianjin University, Tianjin 300072, China \\ ${ }^{2}$ School of Economics and Management, Dezhou University, Dezhou 253023, China \\ ${ }^{3}$ College of Science, Tianjin University of Science and Technology, Tianjin 300457, China \\ Correspondence should be addressed to Junhai Ma; mjhtju@aliyun.com
}

Received 23 March 2015; Accepted 11 May 2015

Academic Editor: Zenghui Wang

Copyright (C) 2015 Ting Li et al. This is an open access article distributed under the Creative Commons Attribution License, which permits unrestricted use, distribution, and reproduction in any medium, provided the original work is properly cited.

\begin{abstract}
This paper analyses the dynamics of dual-channel energy supply chain model with heterogeneous retailers (as regards the type of expectations' formation). On the basis of analyzing the stabilities of four fixed points in the three-dimensional dynamic system, local stable regions of Nash equilibrium are obtained. Effects of $S$ on the stable regions and profit are studied. Simulation results show that the adjustment of price speed has an obvious impact on the complexity of competition. The performances of the model in different period are measured by using the index of average profit. The results show that unstable behavior in economic system is often an unfavorable outcome. So this paper discusses the application of parameters control method when the model is in chaos and then allows the oligarchs to eliminate the negative effects.
\end{abstract}

\section{Introduction}

A number of industrial and governmental statistical reports show that commerce on the Internet is growing at an attractive rate. It means that consumers can get product from dual-channel which is the traditional retail channel and online direct channel in the market. With the emergence and development of the online channel, much previous research on dual-channel management tends to focus on pricing strategies. Balasubramanian [1] models competition in a dual-channel environment from a strategic perspective and shows that the level of market coverage can be used as a mechanism to control competition. Chiang et al. [2] argue that the vertically integrated direct channel allows a manufacturer to constrain the partner retailer's pricing behavior. Hua et al. [3] show that the difference between the demand transfer ratios in the two channels with respect to lead time and direct sale price and customer acceptance of the direct channel have great effects on the lead time and pricing decisions. Furthermore, some researchers have studied pricing strategies under information asymmetry [4$6]$.

However, most of the discussion grounds are focused on well-established and sophisticated microeconomics of retailers, which prevalently either is in a static context or assumes retailers' perfect foresight. So the above papers are unable to explain the dynamic behaviors of the economic system. The dual-channel market describes the structure of oligarch competition model. It is the main characteristic of interdependence that makes oligarch consider the reaction of the competitor. In an oligarch competition, the firms are either output or price setters; refer to Cournot [7] and Bertrand [8]. Rand [9] may be the first man who suggested that the Cournot adjustment process may also fail to converge to a Nash equilibrium and may also exhibit cyclical and even chaotic dynamics. Puu [10-12] found that the Cournot duopoly model can appear as a strange attractor with fractal dimension, and he studied the strategy of the duopoly game. Agiza et al. [13-15] have studied the complex dynamics of abounded rationality duopoly game with a nonlinear demand 
function. The modification of the duopoly game depends on the strategy that the firms use, such as homogeneous and heterogeneous, and the expectations of the output the firms have to maximize, such as bounded rationality, naive expectation, and adaptive expectation. Bischi et al. [16-18] gave the general formula of the oligopoly model with a form of bounded rationality. They discussed the global and local stability of the duopoly game with a particular form of bounded rationality. $\mathrm{Ma}$ and $\mathrm{Pu}$ [19] studied complex behaviors of a CournotBertrand mixed duopoly model with the application of nonlinear dynamics theory. Wang and Ma [20], based on the players with bounded rationality, proposed a CournotBertrand mixed game model and discussed the stability of the system. Aims of all the modifications previously mentioned or not are to make oligarch competition model become economically more justified in the world. In recent years, several scholars have considered more realistic questions, such as Ma et al. [21, 22] who studied bounded rational oligarch game from insurance and R\&D input competition market; they found the chaos phenomenon and proposed some control methods.

In our paper, we considered one online direct retailer and one dual-channel retailer in the market. We assumed that the dual-channel retailer made price decision through both network and traditional channel. Based on the analysis of this situation, we established the corresponding dynamic price game model. Local stable regions of Nash equilibrium and effects of $S$ on the stable regions and profit are studied. Adjustment of price speed has an obvious impact on the complexity of competition. The results show that unstable behavior in economic system is often an unfavorable outcome.

So the rest of this paper is as follows: In Section 2, we describe the model of dual-channel Bertrand Game with heterogeneous expectations. In Section 3, we study the local stability of equilibrium points in the model. In Section 4, we do simulation. In Section 5, the control measure is adopted. Finally, some conclusions are drawn in Section 6.

\section{Model Framework}

2.1. Assumptions. The model is based on the following assumptions:

(1) The dual-channel retailer and online direct retailer sell similar products from different channels on the basis of price competition.

(2) The two retailers are with heterogeneous expectations. The dual-channel retailer is bounded rationality and the online direct retailer is thinking with adaptive expectations.

(3) The dual-channel retailers and online direct retailer have the same cost.

2.2. Model Construction. We consider two oligopoly retailers in supply chain: one retailer sells products to consumers through network and the traditional store, while the other sells products to consumers only through the Internet. The structure of supply chain is as shown in Figure 1. Different from the classic Bertrand model which is a special game model with price as its decision varies, the dual-channel retailer makes price decision both in the tradition channel and network channel. The online direct retailer makes price decision in network channel.

The demand function is given by

$$
\begin{aligned}
& q_{d 0}=s a-b p_{0}+\beta_{1} p_{1}+\beta_{2} p_{2}, \\
& q_{d 1}=(1-s) a-b p_{1}+\beta_{0} p_{0}+\beta_{2} p_{2}, \\
& q_{n}=(1-s) a-b p_{2}+\beta_{1} p_{1}+\beta_{0} p_{0} .
\end{aligned}
$$

Here subscripts $d, n$ represent the dual-channel retailer and the online direct retailer, respectively. $a(a>0)$ represents the possible largest demand.

$s(0<s<1)$ represents the percentage share of the demand going to traditional channel. $b$ is the coefficient of price elasticity of demand. $\beta_{i}$ is cross-price coefficient which represents the retail price sensitivities of the demands in the traditional channel and direct channel. In reality, $\beta_{i}$ is related to channel loyalty. To make the discussion easier to follow, we let $\beta_{0}=\beta_{1}=\beta_{2}=\beta$.

The cost function is linear, so the profit function of dualchannel retailer is

$$
\pi_{d}=p_{0} q_{d 0}+p_{1} q_{d 1}-c\left(q_{d 0}+q_{d 1}\right)
$$

The profit function of online retailer is

$$
\pi_{n}=\left(p_{2}-c\right) q_{n}
$$

Based on first-order conditions of the profit function $\partial \pi / p=0$, we can calculate the optimal reaction function of each retailer, and the intersection of reaction function (4) is the Bertrand Nash equilibrium point:

$$
\begin{aligned}
& p_{0}=\frac{2 \beta p_{1}+\beta p_{2}+a s+c(b-\beta)}{2 b}, \\
& p_{1}=\frac{2 \beta p_{0}+\beta p_{2}+a(1-s)+c(b-\beta)}{2 b}, \\
& p_{2}=\frac{b c+\beta p_{0}+\beta p_{1}+a(1-s)}{2 b} .
\end{aligned}
$$

As the price of the game among retailers is ongoing, price game process is repeated in the complex process for a long term. In oligopoly, game players can choose simple expectation rules such as naive or complicated as adaptive expectations and bounded rationality. The players can use the same strategy (homogeneous expectations) [23,24] or can use different strategy (heterogeneous expectations). In this study we consider heterogeneous retailers such that each retailer thinks with different strategy to maximize his outputs.

We assume the dual-channel is bounded rationality player $[17,25,26]$. In reality, he could only get part of market information; hence they try to use local information based on estimation of marginal profit in the current period. That is, if the current marginal profit is positive, the retailer will 


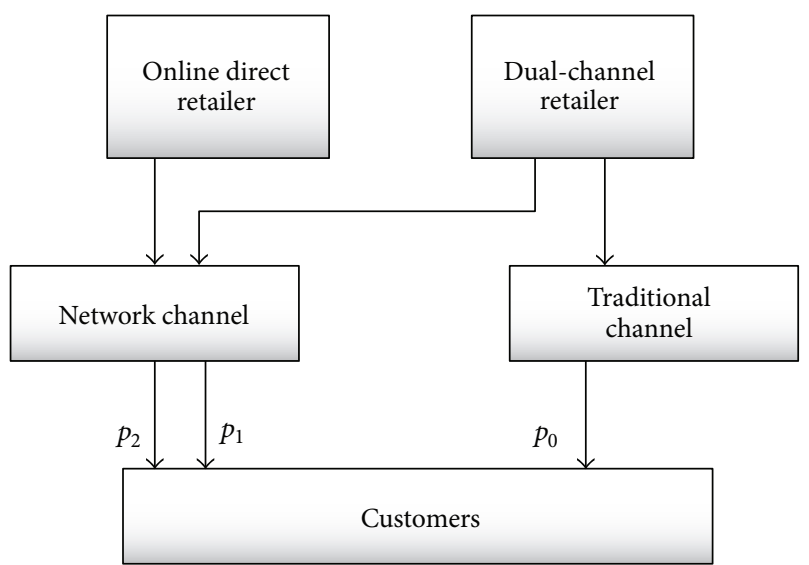

FIGURE 1: The structure of dual-channel energy supply chain.

raise his price in the next period. Otherwise, he will reduce it. The price adjustment process is

$$
\begin{aligned}
p_{i}(t+1)=p_{i}(t)+\alpha_{i} p_{i}(t) \frac{\partial \pi_{i}\left(p_{0}, p_{1}, p_{2}\right)}{\partial p_{i}(t)}, & \\
& \left(0 \leq \alpha_{i} \leq 1\right), i=0,1,
\end{aligned}
$$

where $\alpha_{i}$ is a positive parameter which represents the relative speed of price adjustment.

The online direct retailer can revise their beliefs according to the adaptive expectations rules. If the online direct retailer thinks with adaptive expectations [27, 28], its outputs are obtained with weights between last period's price decision and his reaction function (4). Hence the dynamic equation of the adaptive expectation retailer has the form

$$
p_{2}(t+1)=p_{2}(t)+v\left(p_{2}(t)^{*}-p_{2}(t)\right), \quad(0 \leq v \leq 1)
$$

where $v$ is the speed of adjustment parameter of an adaptive player. If $v=1$ then (6) of adaptive expectations is identical to naive expectation. This implies that naive expectation is a special case of adaptive expectations behavior.

Then we get a discrete dynamic system of the dualchannel game model as follows:

$$
\begin{aligned}
& p_{0}(t+1)=p_{0}(t)+\alpha_{0} p_{0}(t)\left(2 \beta p_{1}(t)-2 b p_{0}(t)\right. \\
& \left.\quad+\beta p_{2}(t)+a s+c(b-\beta)\right), \\
& p_{1}(t+1)=p_{1}(t)+\alpha_{1} p_{1}(t)\left(2 \beta p_{0}(t)-2 b p_{1}(t)\right. \\
& \left.\quad+\beta p_{2}(t)+a(1-s)+c(b-\beta)\right), \\
& p_{2}(t+1)=p_{2}(t) \\
& \quad+v\left(\frac{b c+\beta p_{0}(t)+\beta p_{1}(t)+a(1-s)}{2 b}-p_{2}(t)\right) .
\end{aligned}
$$

\section{Model Analysis}

3.1. Equilibrium Solutions. In system (7), let $p_{i}(t+1)=p_{i}(t)$; then

$$
\begin{aligned}
& p_{0}(t)\left(2 \beta p_{1}(t)-2 b p_{0}(t)+\beta p_{2}(t)+a s+c(b-\beta)\right) \\
& \quad=0 \\
& p_{1}(t)\left(2 \beta p_{0}(t)-2 b p_{1}(t)+\beta p_{2}(t)+a(1-s)\right. \\
& \quad+c(b-\beta))=0 \\
& \frac{b c+\beta p_{0}(t)+\beta p_{1}(t)+a(1-s)}{2 b}-p_{2}(t)=0 .
\end{aligned}
$$

We can get the equilibrium solutions. Before we solve for the equilibrium solutions of system (7), firstly, we assign some values to parameters by considering actual competition. Let $a=4, b=0.7, s=0.6, c=1, \beta=0.3$. Then we get the four equilibrium solutions of system, which are

$$
\begin{aligned}
& E_{1}=(0,0,1.643), \\
& E_{2}=(2.465,0,2.171), \\
& E_{3}=(0,1.866,2.043), \\
& E_{4}=(4.509,4.109,3.489) .
\end{aligned}
$$

Obviously, $E_{1}, E_{2}$, and $E_{3}$ are boundary equilibrium solutions, while $E_{4}$ is the only Nash equilibrium solution.

3.2. Stability of Equilibrium Solutions. To study the stability of the equilibrium solutions, we will calculate the Jacobian matrix of system (7):

$$
J(E)=\left(\begin{array}{ccc}
U_{1} & 2 \beta \alpha_{0} p_{0} & \beta \alpha_{0} p_{0} \\
2 \beta \alpha_{1} p_{1} & U_{2} & \beta \alpha_{1} p_{1} \\
\frac{\beta v}{2 b} & \frac{\beta v}{2 b} & 1-v
\end{array}\right),
$$

where

$$
\begin{aligned}
U_{1}= & 1+\alpha_{0}\left(2 \beta p_{1}-2 b p_{0}+\beta p_{2}+a s+c(b-\beta)\right) \\
& -2 b \alpha_{0} p_{0}, \\
U_{2}= & 1 \\
& +\alpha_{1}\left(2 \beta p_{0}-2 b p_{1}+\beta p_{2}+a(1-s)+c(b-\beta)\right) \\
& -2 b \alpha_{1} p_{1} .
\end{aligned}
$$

Then we put the value of $E_{1}, E_{2}$, and $E_{3}$ into (10); according to the conditions for the stability of equilibrium solutions, the moduli of all characteristic roots should be less than 1 [29]. So we can see that $E_{1}, E_{2}$, and $E_{3}$ are unstable equilibrium solutions.

At the Nash equilibrium point $E_{4}=(4.509,4.109,3.489)$, its Jacobian matrix is

$$
J\left(E_{4}\right)=\left(\begin{array}{ccc}
1-6.313 \alpha_{0} & 2.705 \alpha_{0} & 1.353 \alpha_{0} \\
2.465 \alpha_{1} & 1-5.753 \alpha_{1} & 1.233 \alpha_{1} \\
0.2143 v & 0.2143 v & 1-v
\end{array}\right) .
$$




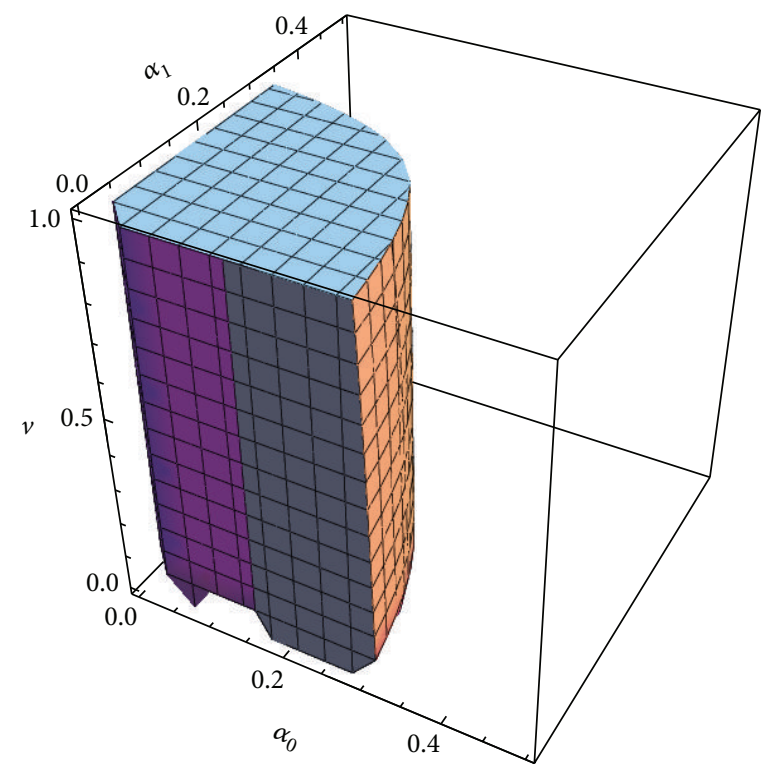

(a)

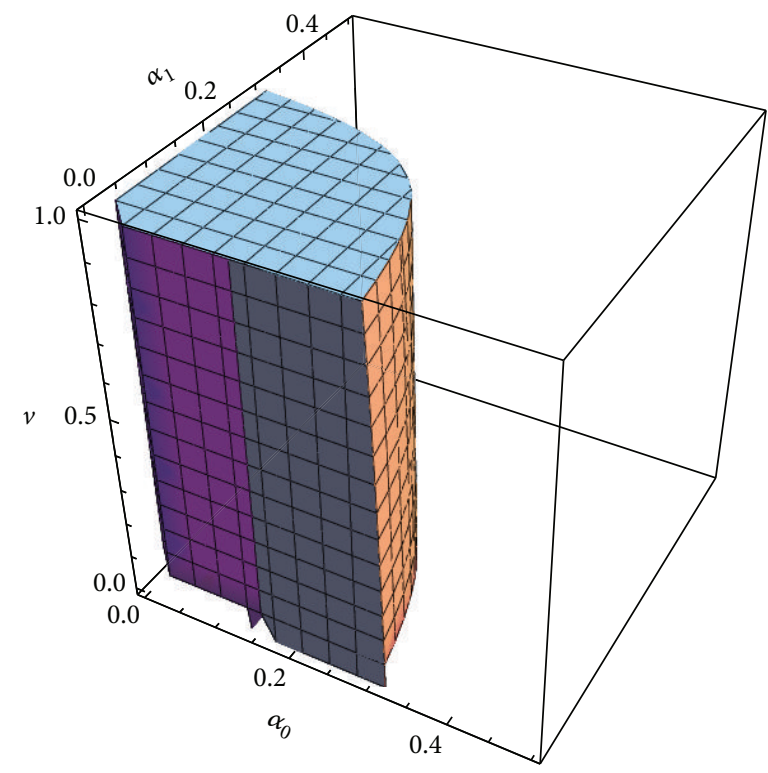

(c)

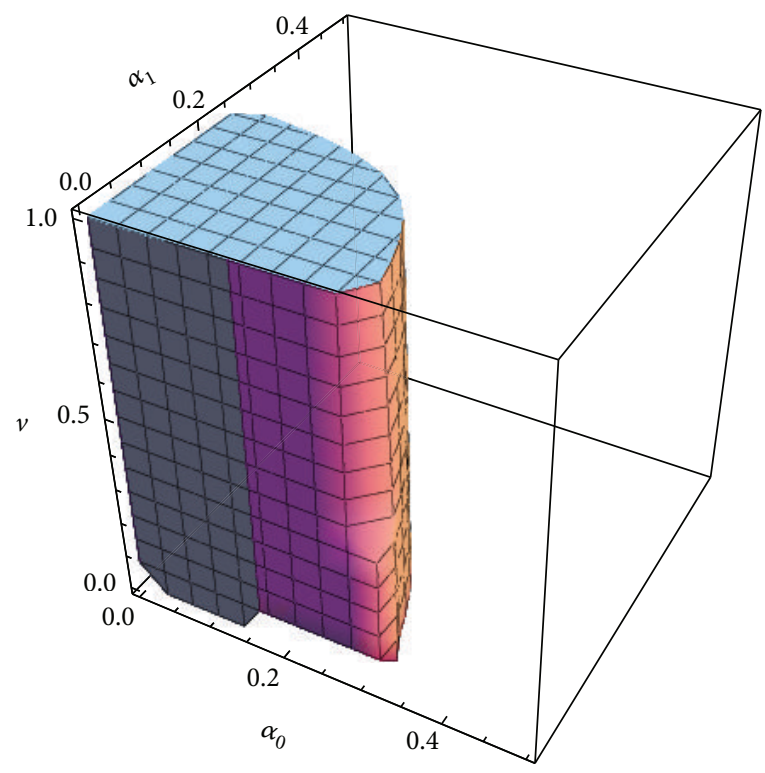

(b)

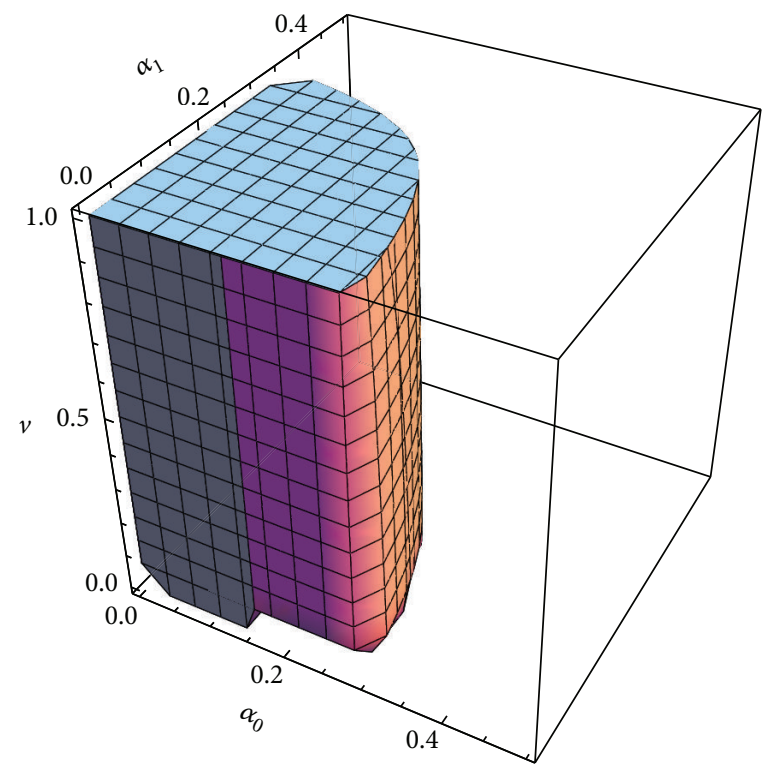

(d)

FiguRE 2: (a) Three-dimensional stable region, $S=0.6$. (b) Three-dimensional stable region, $S=0.3$. (c) Three-dimensional stable region, $S=0.5$. (d) Three-dimensional stable region, $S=0.7$.

And the characteristic equation of $J\left(E_{4}\right)$ is $\lambda^{3}-A \lambda^{2}-B \lambda-C=$ 0 , where

$$
\begin{aligned}
A= & 6.31 \alpha_{0}+5.75 \alpha_{1}+v-3 \\
B= & 6+6.02 v \alpha_{0}-2 v-5.49 v \alpha_{1}-12.63 \alpha_{0}-11.50 \alpha_{0} \\
& +29.65 \alpha_{0} \alpha_{1}, \\
C= & 6.31 \alpha_{0}+5.75 \alpha_{1}-6.02 v \alpha_{0}-5.49 v \alpha_{1} \\
& +24.89 v \alpha_{0} \alpha_{1}+v-1-29.65 \alpha_{0} \alpha_{1} .
\end{aligned}
$$

According to the Jury stability criterion, the necessary and sufficient condition of asymptotic stabilization at $E_{4}$ is that all zero points of the characteristic polynomial are inside the unit circle of the complex plane. So the following four conditions must be met:

$$
\begin{aligned}
& f(1)=1-A-B-C>0, \\
& -f(-1)=-A+B-C+1>0, \\
& 1-C^{2}>0 \\
& \left(1-C^{2}\right)^{2}-(B+A C)^{2}>0 .
\end{aligned}
$$

Conditions (14) define a region of system stability in the place of the adjustment parameters which can be shown in Figure 2(a). Equations (14) are conditions for local stability 
of the Nash equilibrium $E_{4}$ which is asymptotically stable with the values of $\left(\alpha_{0}, \alpha_{1}, v\right)$. In the stable region, the price will reach the Nash equilibrium point by modulating limited times with random initial price. If the values of $\left(\alpha_{0}, \alpha_{1}, v\right)$ are out of the stable region, the market will lose stability or even fall into chaos.

As can be seen in Figure 2, the system is stable in $v \in$ $[0,1]$, which means $v$ almost has no influence on the stability of system. The market is stable when $v \in[0,1]$ and the values of $\alpha_{i}$ are small, but the market may be unstable when $\alpha_{i}$ increases. In the stable region shown in Figure 2, ranges of $\alpha_{0}$ and $\alpha_{1}$ are almost the same.

The economic meaning of the stable region is that if the value of $\left(\alpha_{0}, \alpha_{1}, v\right)$ is in the stable region, prices of three firms, $p_{1}, p_{2}$, and $p_{3}$, will achieve the Nash equilibrium price after a number of games. Firm 1 and firm 2 should control their price adjustment speed to maintain the market stability.

3.3. Effect of $S$ on the Stable Regions and Profit. In order to show the effects of the percentage share of the demand in traditional channel on the stable regions, we set $S=0.3,0.5$, 0.7 , respectively; according to the parameters above, we can get Figures 2(b), 2(c), and 2(d).

As can be seen from the comparison of Figures 2(a)-2(d), with the increase of the percentage share of the demand in traditional channel $S$, ranges of $\alpha_{1}$ expand while ranges of $\alpha_{0}$ narrow. From the perspective of economics, in order to keep the market stable, the smaller the percentage share of the demand in traditional channel $(S)$, the larger the rang of the price adjustment speed of the traditional channel firm $\left(\alpha_{0}\right)$ and the smaller the rang of the price adjustment speed of the network channel firm $\left(\alpha_{1}\right)$.

When we set $S=0.3,0.5,0.6,0.7$, respectively; the Nash equilibrium $E_{4}$ is also different which can be shown in Table 1 .

According to the profit function of dual-channel retailer and the profit function of online retailer, $\pi_{d}=p_{0} q_{d 0}+p_{1} q_{d 1}-$ $c\left(q_{d 0}+q_{d 1}\right)$ and $\pi_{n}=\left(p_{2}-c\right) q_{n}$. The Nash profit equilibrium is also shown in Table 1.

As can be seen from the comparison of Figures 2(a)-2(d), with the increase of the percentage share of the demand in traditional channel $(S)$, Nash equilibrium price $\left(p_{0}\right)$ in traditional channel increases; Nash equilibrium prices $\left(p_{1}, p_{2}\right)$ in network channel decrease.

With the increase of the percentage share of the demand in network channel $(1-S)$, Nash equilibrium profit of all the retailers increases.

3.4. Parameter Basin Plots. Figures 3, 4, and 5 present the parameter basin plots in the $\left(\alpha_{1}, \alpha_{2}\right)$ with different value of parameter $v$, in which different colors represent different states. The light blue indicates stable steady state and red is for cycles of period 2, green for cycles of period 3, yellow for cycles of period 4 , black for cycles of period 5 , pink for cycles of period 8, dark blue for chaos, and white for divergence (which means one of the players will be out of the market in economics). We can find that when the parameters $\left(\alpha_{1}, \alpha_{2}\right)$ from the light blue area pass through yellow, pink, and dark blue areas in turn, system (7) enters into chaos through flip

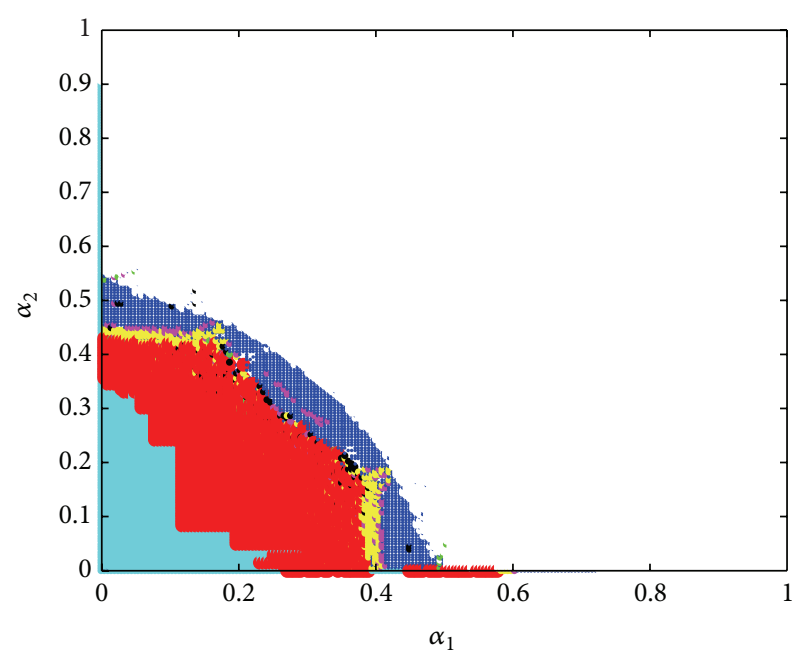

FIgURE 3: The parameter basin when $v=0.2$.

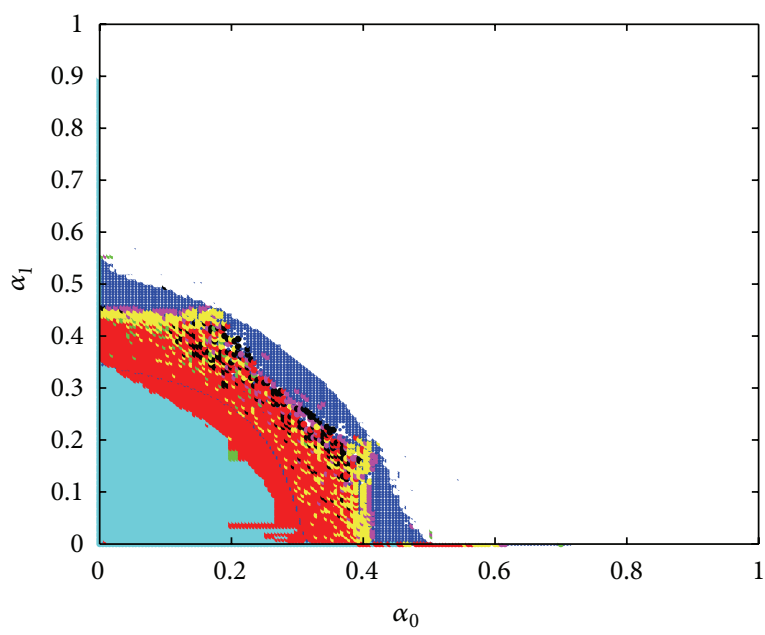

Figure 4: The parameter basin when $v=0.5$.

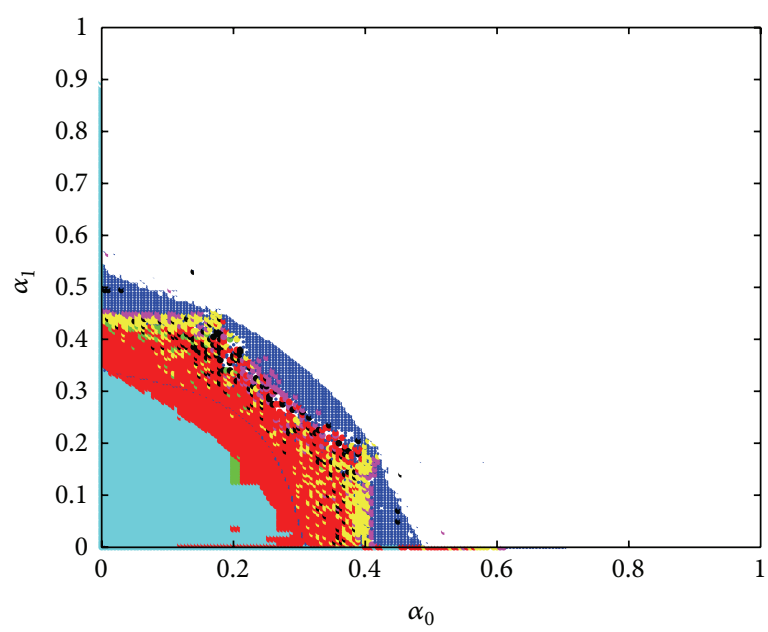

Figure 5: The parameter basin when $v=0.8$. 
TABLE 1: Nash equilibrium and Nash profit equilibrium with different $S$.

\begin{tabular}{|c|c|c|c|c|}
\hline$S$ & 0.3 & 0.5 & 0.6 & 0.7 \\
\hline Nash equilibrium & $\begin{array}{l}p_{0}=4.2915 ; \\
p_{1}=5.0915 ; \\
p_{2}=4.5106\end{array}$ & $\begin{array}{l}p_{0}=4.4362 ; \\
p_{1}=4.4362 ; \\
p_{2}=3.8298\end{array}$ & $\begin{array}{l}p_{0}=4.5085 \\
p_{1}=4.1085 \\
p_{2}=3.4894\end{array}$ & $\begin{array}{l}p_{0}=4.5809 ; \\
p_{1}=3.7809 ; \\
p_{2}=3.1489 ;\end{array}$ \\
\hline Nash profit equilibrium & $\begin{array}{c}\pi_{d}=11.22 \\
\pi_{n}=8.63\end{array}$ & $\begin{aligned} \pi_{d} & =9.45 \\
\pi_{n} & =5.61\end{aligned}$ & $\begin{aligned} \pi_{d} & =8.84 \\
\pi_{n} & =4.34\end{aligned}$ & $\begin{array}{l}\pi_{d}=8.41 \\
\pi_{n}=3.23\end{array}$ \\
\hline
\end{tabular}

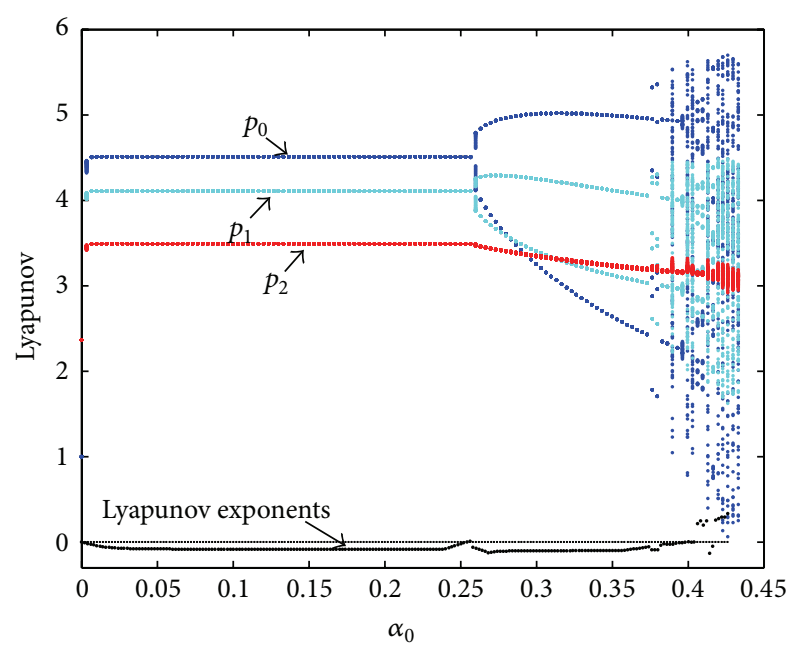

FIGURE 6: Lyapunov exponent and bifurcation diagram with $\alpha_{0}$ when $\alpha_{1}=0.2, v=0.2$.

bifurcation. When $\left(\alpha_{1}, \alpha_{2}\right)$ from the black go to the dark blue area directly, system (7) enters into chaos through NeimarkSacker bifurcation.

\section{Numerical Simulations for System}

The main goal of this section is to show that the complicated dynamic features of the dual supply model with heterogeneous retailers. To provide some numerical evidence for the chaotic behavior of system (7), we present various numerical results here to show the chaoticity, including its bifurcations diagrams, Lyapunov exponents, strange attractors, and sensitive dependence on initial conditions. In order to study the properties of the dynamic model, it is convenient to take the parameters values assigned above.

4.1. The Effect of the Price Adjustment Speed. Figure 6 describes the Lyapunov exponents and price bifurcation with change of $\alpha_{0}$ when $\alpha_{1}=0.2, v=0.2$. As shown in Figure 3, the Nash equilibrium point is stable at $\alpha_{0}<0.2508$. With $\alpha_{0}$ increasing, the stability of equilibrium point changes; the system experiences period-doubling bifurcation and falls into chaos eventually. The positive Lyapunov exponent is used to mark the chaos. The system is in chaos when most of the Lyapunov exponents are positive. Figure 7 shows a chaos attractor of system (7), which is another characteristic of the system. The sensitive dependence on initial conditions is one of the important features of chaos. Figure 8 shows the changes

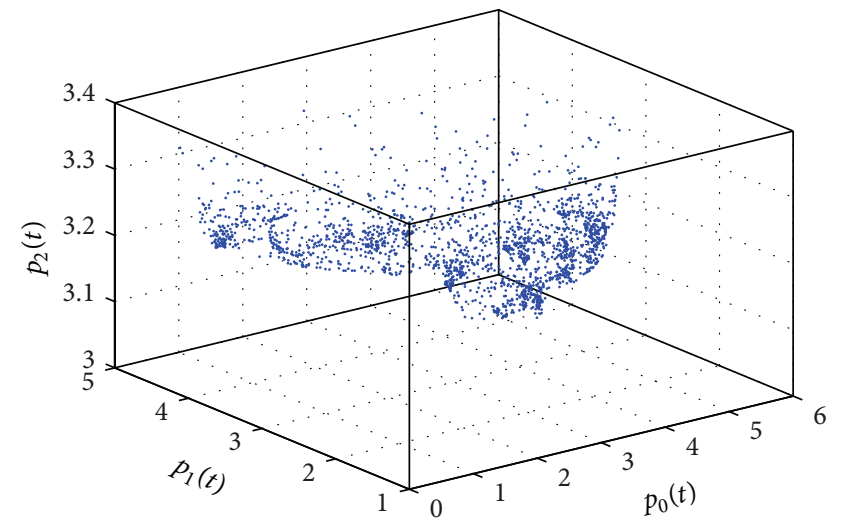

FIGURE 7: Chaotic attractor of the system when $\alpha_{0}=0.42, \alpha_{1}=0.2$.

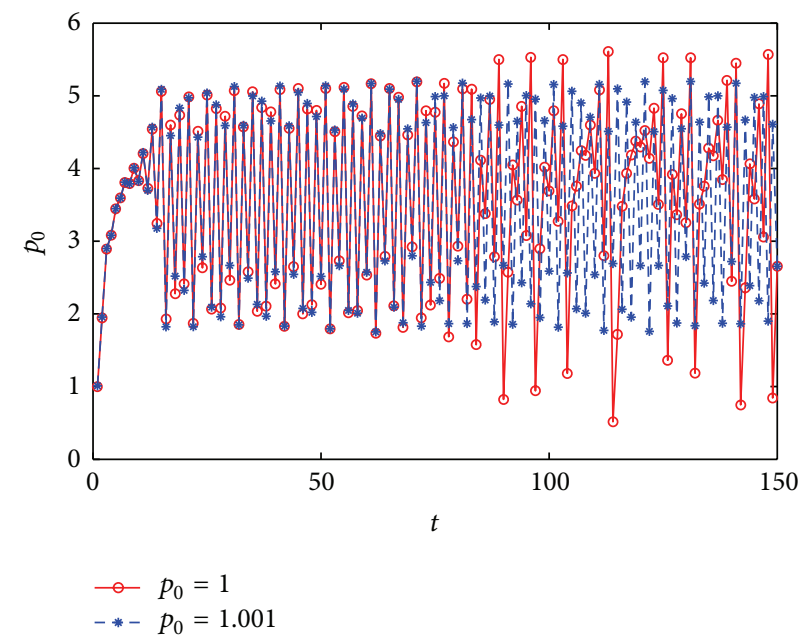

FIGURE 8: Sensitivity dependence to initial condition when system in chaos period.

of retailers different price separately with process of games when $\left(p_{0}, p_{1}, p_{2}\right)=(1,1,1)$ and $\left(p_{0}, p_{1}, p_{2}\right)=(1.001,1,1)$. From Figure 8 we can see that when $p_{0}$ changes a little, the price decision will have distinct changes. Now we have studied the dynamic behavior in system (7) with change of $v$. Figure 9 shows that the changes of parameter $v$ have no effect on system (7) when $\alpha_{0}=0.2, \alpha_{1}=0.2$; this means that the Nash equilibrium point is stable for $0 \leq v \leq 1$.

4.2. The Effect of Parameters Changes on the Profit. Figure 10 shows the profit of the two retailers in 50 games when 


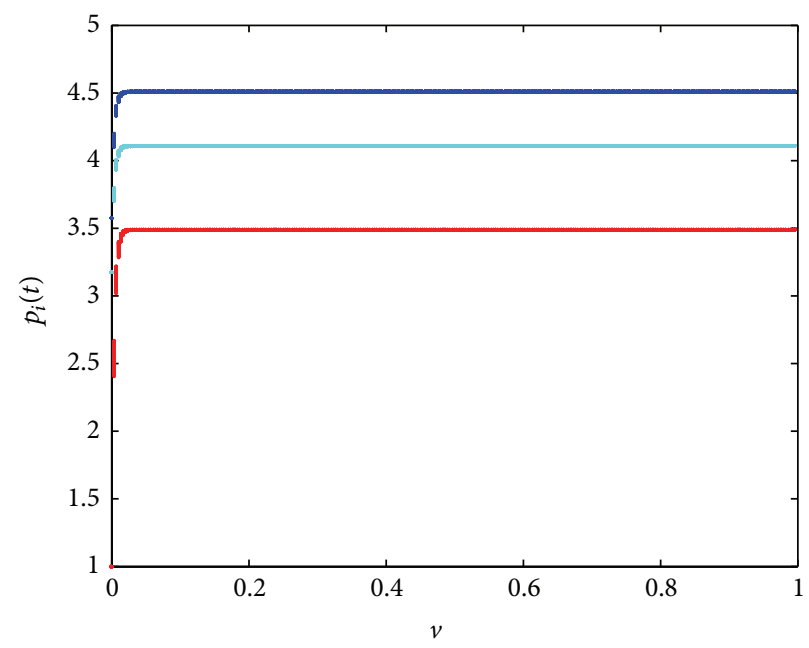

FIGURE 9: Bifurcation diagram with $v$ when $\alpha_{1}=0.2, \alpha_{2}=0.2$.

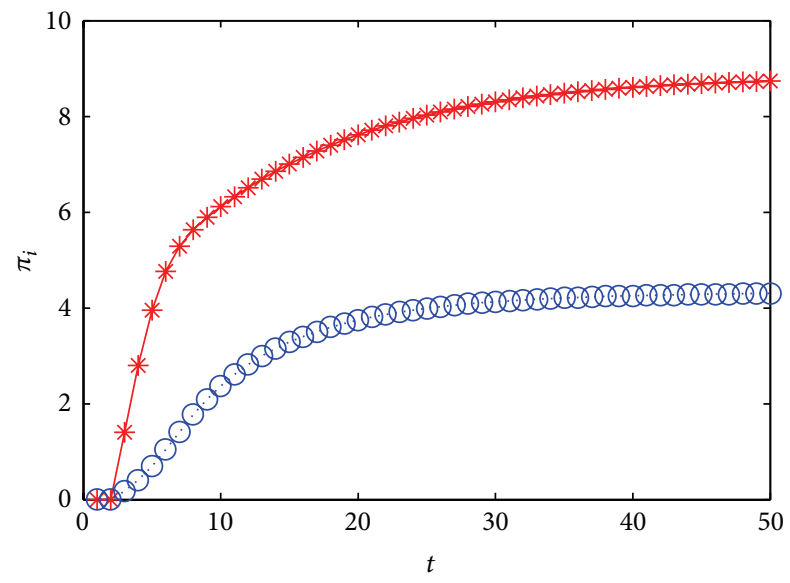

(a)

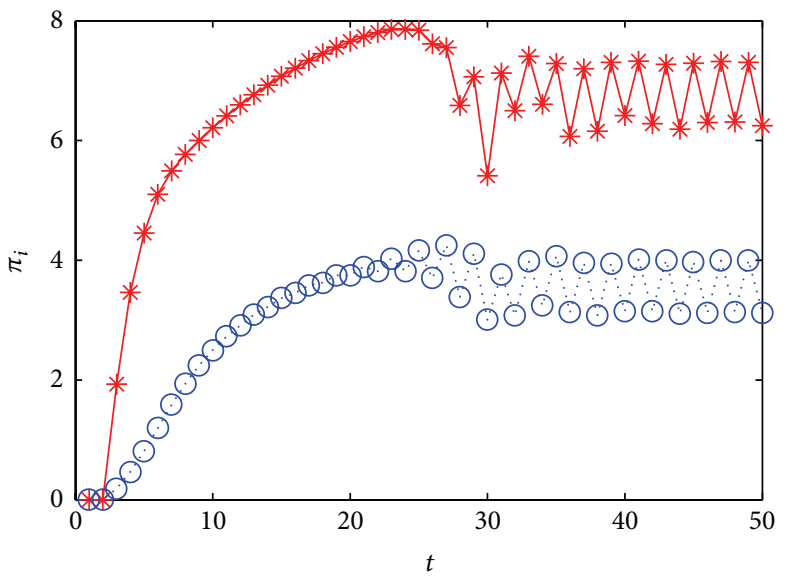

(b)

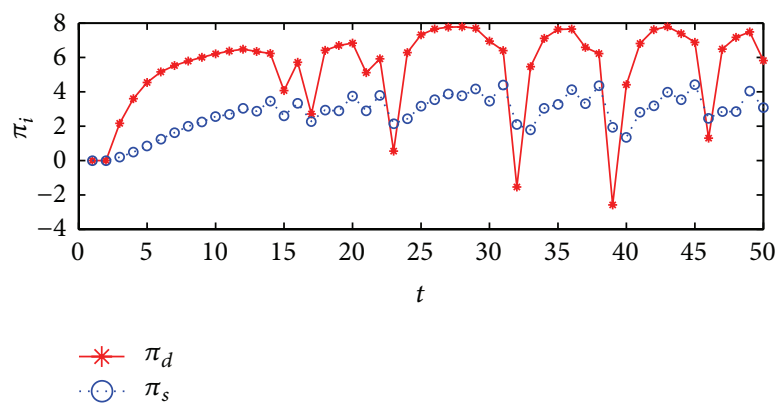

(c)

FIgURE 10: The profits of retailers when system in (a) stable period; (b) two period-doubling bifurcations; (c) chaotic period.

the system is in a stationary period, two period-doubling bifurcations, and a chaotic period. Figure 11 shows the average profits of both retailers with respect to the change of $\alpha_{0}$. From the figure, we see that when the price adjustment speed increases, the system goes through different stages. So we can make conclusions that the profit of the two retailers in a chaotic period is less than that in other periods. These explain why chaos is undesirable in the real market.

\section{Chaos Control}

Our study found that once the market is in chaos, the total profit of the system is less than that in the equilibrium state, so this kind of state is not expected to appear. However, the current situation is that the oligarchs often maximize profit by any kind of means in the process of marketization. So the market will be out of order and finally fall into chaos. 


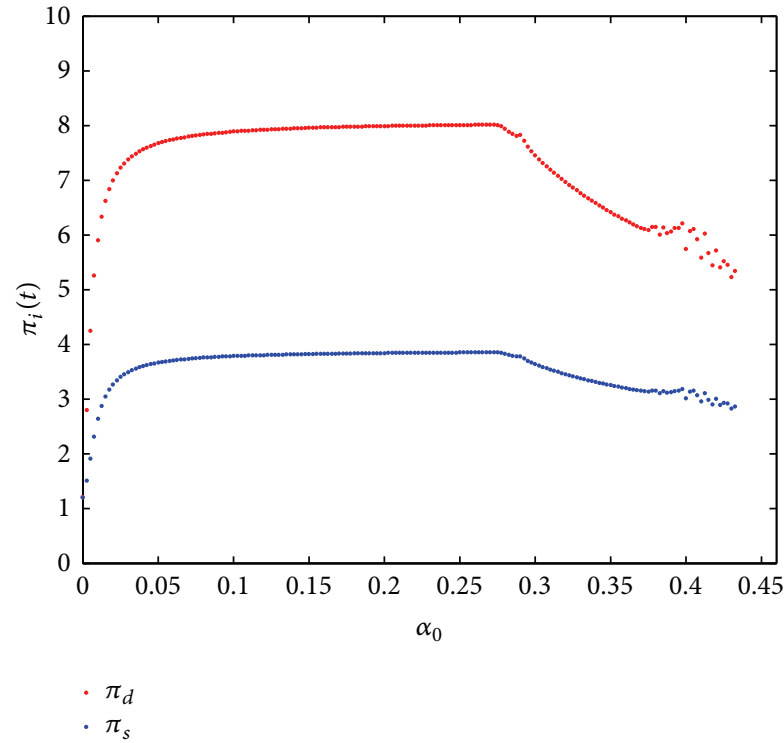

FIgURE 11: The change of average profits with respect to $\alpha_{0}$.

It is particularly important for each party that some control measures need to be adopted timely to make the system return to its stable equilibrium. Therefore, we propose the adaptive adjustment mechanism $[30,31]$ to control system (7). Assume system (7) is generally described by $p_{i}(t+1)=$ $f_{i}\left(p_{0}(t), p_{1}(t), p_{2}(t)\right)$. Then the controlled system is

$$
\begin{aligned}
p_{0}(t+1)= & (1-\tau) g_{0}\left(p_{0}(t), p_{1}(t), p_{2}(t)\right) \\
& +\tau p_{0}(t), \\
p_{1}(t+1)= & (1-\tau) g_{1}\left(p_{0}(t), p_{1}(t), p_{2}(t)\right) \\
& +\tau p_{1}(t), \\
p_{2}(t+1)= & (1-\tau) g_{2}\left(p_{0}(t), p_{1}(t), p_{2}(t)\right) \\
& +\tau p_{2}(t),
\end{aligned}
$$

where $\tau$ is the adjustment parameter. Figure 12 shows the bifurcation diagram of price against the adaptive parameter $\tau$. From Figure 12, with control parameter $\tau$ increasing, chaotic system was gradually controlled at Nash equilibrium solutions. Figure 13 shows the cases of control parameters $\tau=$ 0.2 and $\tau=0.35$, under which the system rapidly converges to aperiodic- 2 orbits and the Nash equilibrium solutions, respectively. In real market, we can consider $\tau$ a learning ability or adaptability of market. For instance, the retailers analyzed the information in the past and then adopted proper price adjustment speed.

\section{Conclusions}

In this study, a dual-channel supply chain model with a traditional retailer and an online direct retailer is proposed.

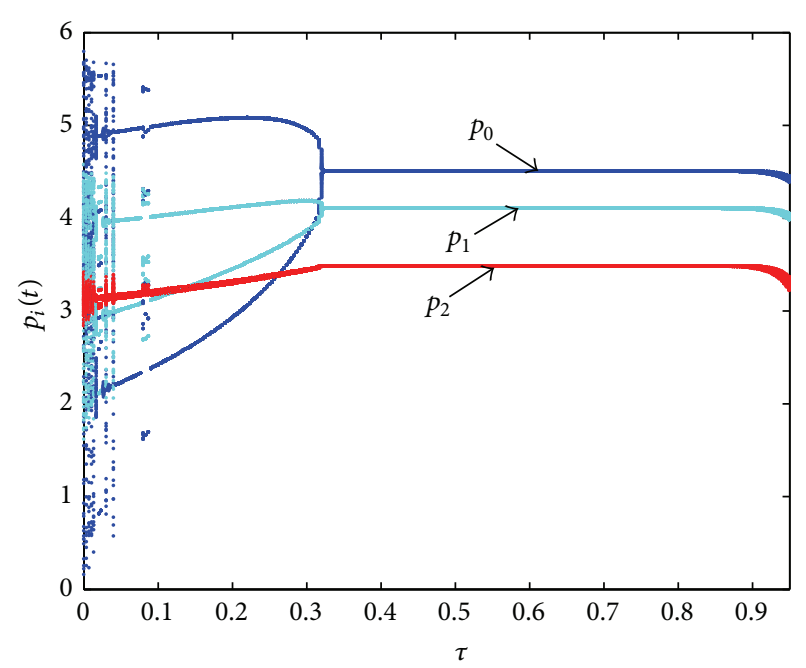

FIGURE 12: Bifurcation diagram with change of the control parameter $\tau$.

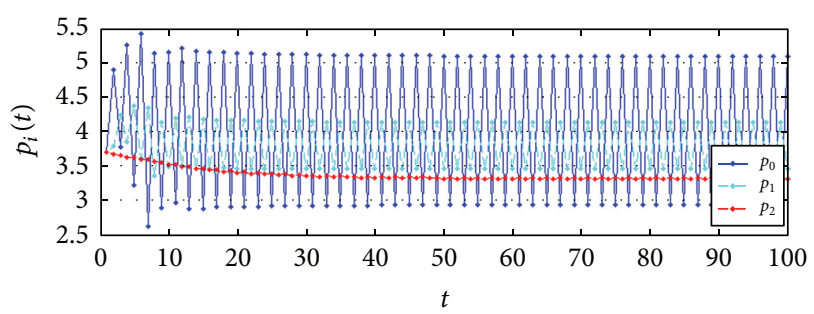

(a)

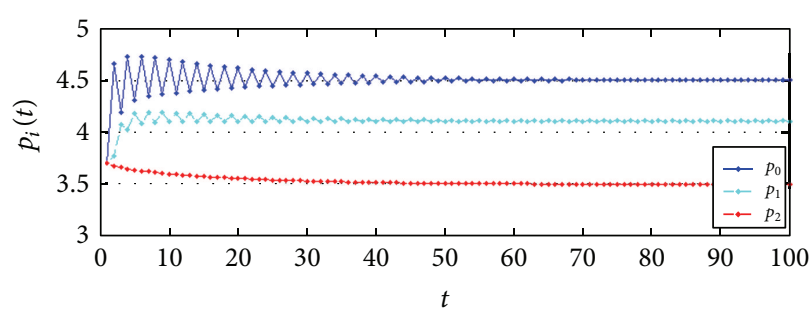

(b)

FIGURE 13: Time history of prices of the retailers (a) $\tau=0.2$ and (b) $\tau=0.35$.

Highlights of innovation included in the paper are the following 2 points:

(1) Performances of the model in different period are measured by using the index of average profit.

(2) Unstable behavior in economic system often brings an unfavorable outcome.

The bifurcations, chaos, and other complex phenomena were found and the chaotic features are justified numerically via computing Lyapunov exponents, showing the chaotic attractor and sensitive dependence on initial conditions. When chaos occurs, it breaks the whole system, and the market will become abnormal, irregular, and unpredictable. The system's performance was measured by the profits. With the increase of the percentage share of the demand in network 
channel $(1-S)$, Nash equilibrium profit of all the retailers increases. It can be found from our study that the optimal strategy is in the stable region of the Nash equilibrium. Once the market is in chaos, the profits of system are less than that of the system in equilibrium state. At last, we use adaptive adjustment mechanism to control the system, showing that the controlled system can delay chaos or even eliminate chaos completely. So it is particularly important for each retailer to adopt some control measures timely in order to make the system keep in stable state and avoid the loss of system profits.

\section{Conflict of Interests}

The authors declare that there is no conflict of interests regarding the publication of this paper.

\section{Acknowledgments}

The research was supported by the National Natural Science Foundation of China (no. 61273231) and Doctoral Fund of Ministry of Education of China (Grant no. 20130032110073) and supported by The Foundation for Outstanding Young Scientist in Shandong Province (Fund no. BS2014SF021).

\section{References}

[1] S. Balasubramanian, "Mail versus mall: a strategic analysis of competition between direct marketers and conventional retailers," Marketing Science, vol. 17, no. 3, pp. 181-195, 1998.

[2] W.-Y. K. Chiang, D. Chhajed, and J. D. Hess, "Direct marketing, indirect profits: a strategic analysis of dual-channel supplychain design," Management Science, vol. 49, no. 1, pp. 1-20, 2003.

[3] G. Hua, S. Wang, and T. C. E. Cheng, "Price and lead time decisions in dual-channel supply chains," European Journal of Operational Research, vol. 205, no. 1, pp. 113-126, 2010.

[4] D.-Q. Yao and J. J. Liu, "Competitive pricing of mixed retail and e-tail distribution channels," Omega, vol. 33, no. 3, pp. 235-247, 2005.

[5] X. Yue and J. Liu, "Demand forecast sharing in a dual-channel supply chain," European Journal of Operational Research, vol. 174, no. 1, pp. 646-667, 2006.

[6] R. Yan and S. Ghose, "Forecast information and traditional retailer performance in a dual-channel competitive market," Journal of Business Research, vol. 63, no. 1, pp. 77-83, 2010.

[7] A. Cournot, Recherches sur les Principes Mathématiques de la Théorie des Richesses, Hachette, Paris, France, 1838.

[8] J. Bertrand, "Review of Theorie mathematique de la richesse sociale and of Recherches sur les principles mathematiques de la theorie des richesses," Journal des Savants, vol. 67, pp. 499-508, 1883.

[9] D. Rand, "Exotic phenomena in games and duopoly models," Journal of Mathematical Economics, vol. 5, no. 2, pp. 173-184, 1978.

[10] T. Puu, "The chaotic duopolists revisited," Journal of Economic Behavior and Organization, vol. 33, no. 3-4, pp. 385-394, 1998.

[11] T. Puu, "Complex dynamics with three oligopolists," Chaos, Solitons and Fractals, vol. 7, no. 12, pp. 2075-2081, 1996.
[12] T. Puu, "On the stability of Cournot equilibrium when the number of competitors increases," Journal of Economic Behavior \& Organization, vol. 66, no. 3-4, pp. 445-456, 2008.

[13] H. N. Agiza, A. S. Hegazi, and A. A. Elsadany, "Complex dynamics and synchronization of a duopoly game with bounded rationality," Mathematics and Computers in Simulation, vol. 58, no. 2, pp. 133-146, 2002.

[14] H. N. Agiza and A. A. Elsadany, "Chaotic dynamics in nonlinear duopoly game with heterogeneous players," Applied Mathematics and Computation, vol. 149, no. 3, pp. 843-860, 2004.

[15] H. N. Agiza, A. A. Elsadany, and M. M. El-Dessoky, "On a new Cournot Duopoly game," Journal of Chaos, vol. 2013, Article ID 487803, 5 pages, 2013.

[16] G. I. Bischi, L. Gardini, and M. Kopel, "Analysis of global bifurcations in a market share attraction model," Journal of Economic Dynamics and Control, vol. 24, no. 5-7, pp. 855-879, 2000.

[17] G. I. Bischi and A. Naimzadaz, "Global analysis of a dynamic duopoly game with bounded rationality," in Advances in Dynamic Games and Applications, vol. 5 of Annals of the International Society of Dynamic Games, pp. 361-385, Birkhäuser, Boston, Mass, USA, 2000.

[18] G. I. Bischi, L. Sbragia, and F. Szidarovszky, "Learning the demand function in a repeated Cournot oligopoly game," International Journal of Systems Science, vol. 39, no. 4, pp. 403419, 2008.

[19] J. Ma and X. Pu, "The research on Cournot-Bertrand duopoly model with heterogeneous goods and its complex characteristics," Nonlinear Dynamics, vol. 72, no. 4, pp. 895-903, 2013.

[20] H. Wang and J. Ma, "Complexity analysis of a CournotBertrand duopoly game model with limited information," Discrete Dynamics in Nature and Society, vol. 2013, Article ID 287371, 6 pages, 2013.

[21] M. Junhai and Z. Junling, "Research on the price game and the application of delayed decision in oligopoly insurance market," Nonlinear Dynamics, vol. 70, no. 4, pp. 2327-2341, 2012.

[22] T. Li and J. Ma, "The complex dynamics of R\&D competition models of three oligarchs with heterogeneous players," Nonlinear Dynamics, vol. 74, no. 1-2, pp. 45-54, 2013.

[23] T. Dubiel-Teleszynski, "Complex dynamics in Bertrand duopoly games with homogeneous and heterogeneous players," Central European Journal of Economic Modelling and Econometrics, vol. 2, no. 2, pp. 95-116, 2009.

[24] D. Furth, "Anything goes with heterogeneous, but not always with homogeneous oligopoly," Journal of Economic Dynamics and Control, vol. 33, no. 1, pp. 183-203, 2009.

[25] H. N. Agiza, A. S. Hegazi, and A. A. Elsadany, "The dynamics of Bowley's model with bounded rationality," Chaos, Solitons and Fractals, vol. 12, no. 9, pp. 1705-1717, 2001.

[26] A. A. Elsadany, "Competition analysis of a triopoly game with bounded rationality," Chaos, Solitons \& Fractals, vol. 45, no. 11, pp. 1343-1348, 2012.

[27] G. I. Bischi and M. Kopel, "Equilibrium selection in a nonlinear duopoly game with adaptive expectations," Journal of Economic Behavior and Organization, vol. 46, no. 1, pp. 73-100, 2001.

[28] J. Ding, Q. Mei, and H. Yao, "Dynamics and adaptive control of a duopoly advertising model based on heterogeneous expectations," Nonlinear Dynamics, vol. 67, no. 1, pp. 129-138, 2012. 
[29] C. Li, J. Peng, and Q. Huang, "Controlling synchronization of chaos and hyperchaos systems," Journal of Northeast Normal University: Natural Science, vol. 33, no. 3, pp. 43-47, 2001.

[30] W. Huang, "Stabilizing nonlinear dynamical systems by an adaptive adjustment mechanism," Physical Review E-Statistical Physics, Plasmas, Fluids, and Related Interdisciplinary Topics, vol. 61, no. 2, pp. R1012-R1015, 2000.

[31] W. Huang, “Theory of adaptive adjustment," Discrete Dynamics in Nature and Society, vol. 5, no. 4, pp. 247-263, 2000. 


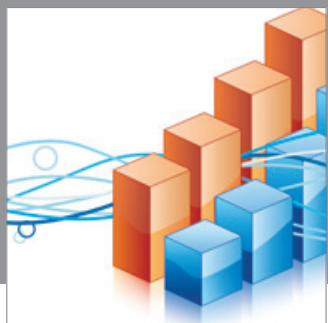

Advances in

Operations Research

mansans

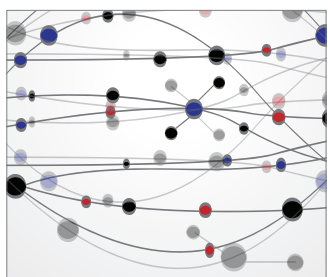

The Scientific World Journal
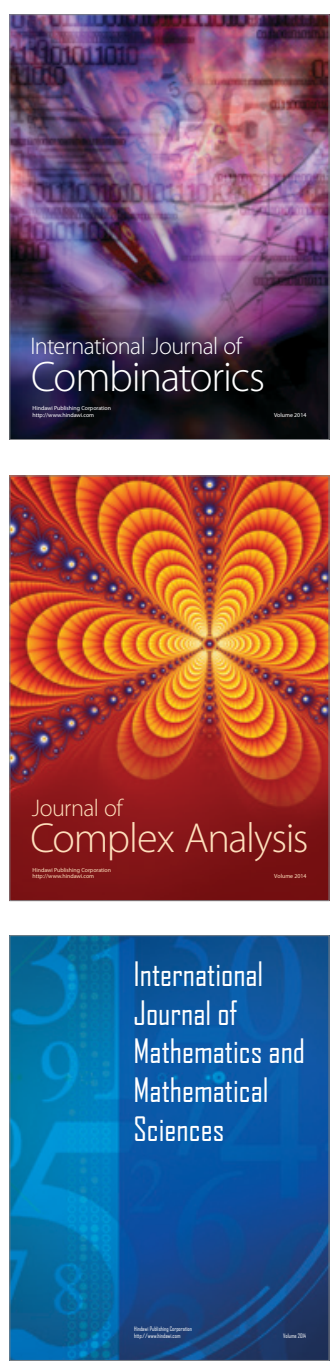
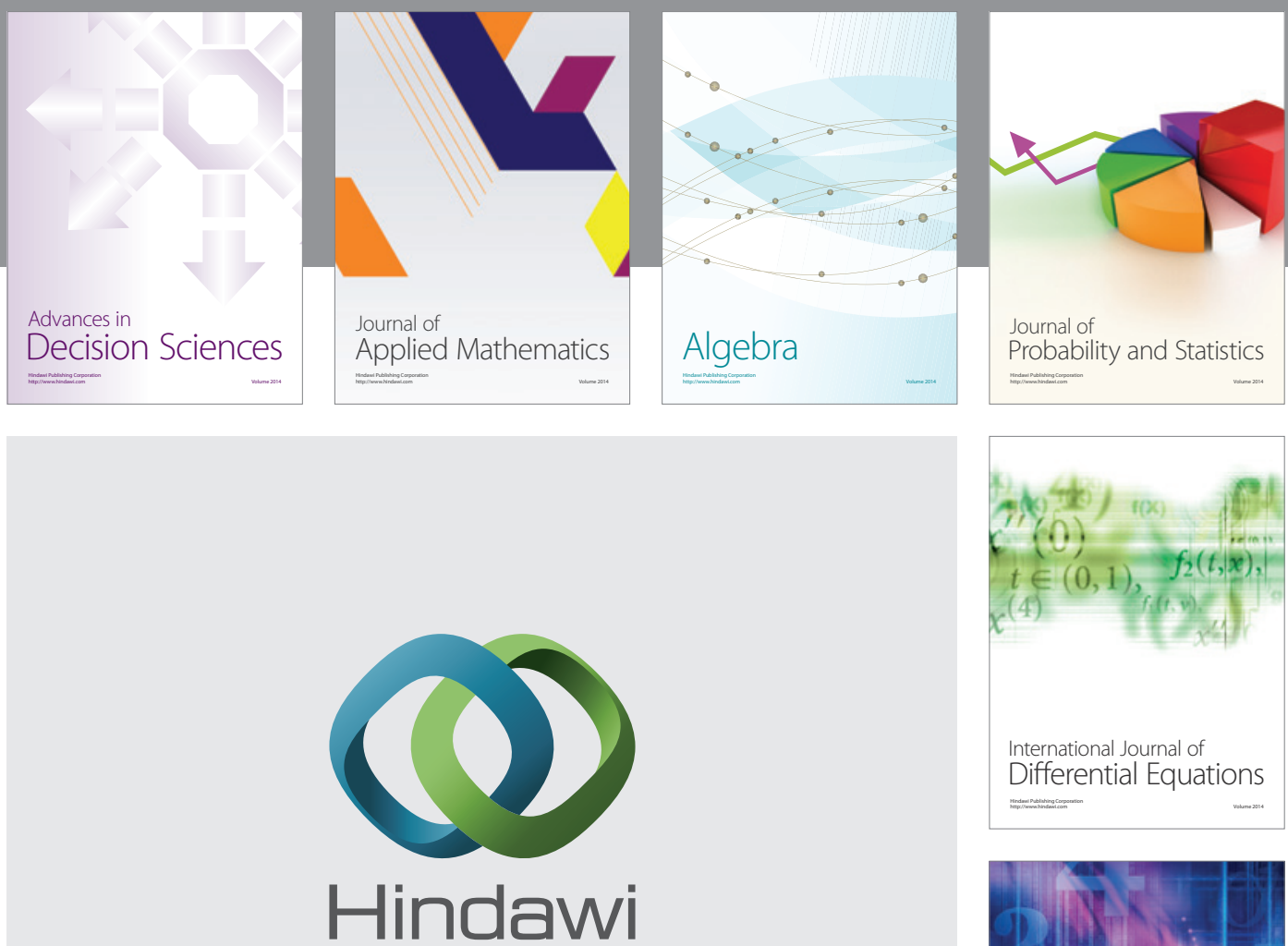

Submit your manuscripts at http://www.hindawi.com
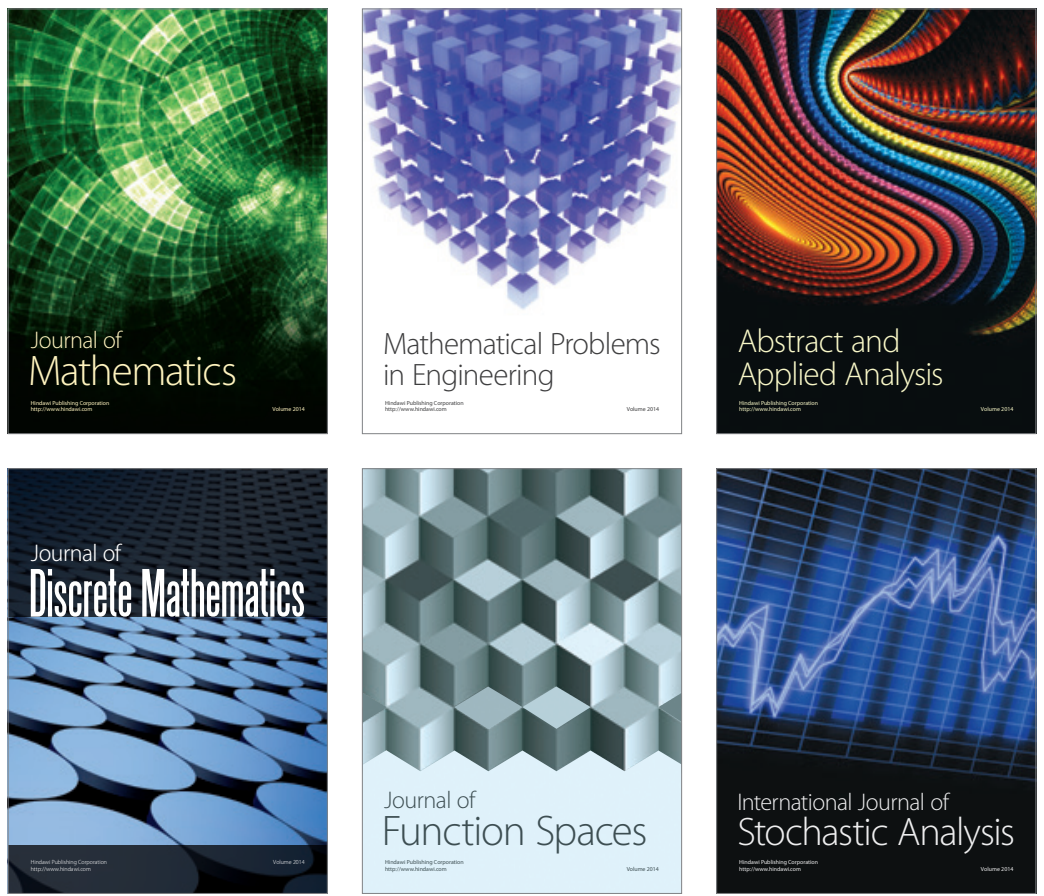

Journal of

Function Spaces

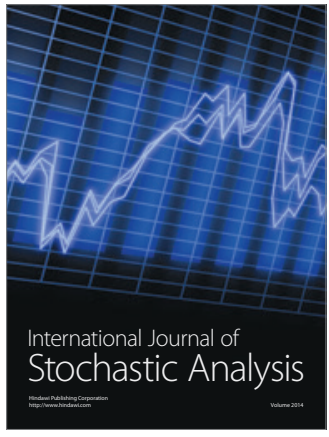

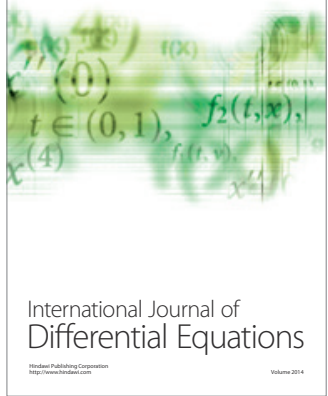
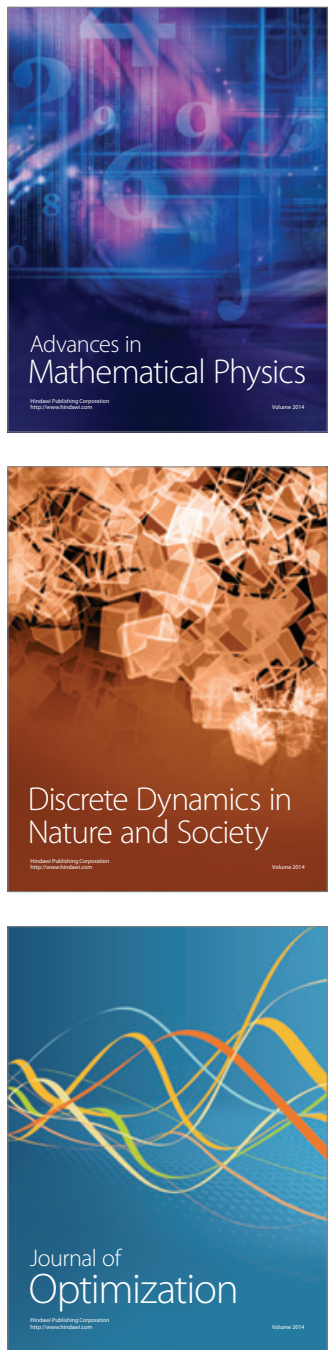